as especies de la familia Tiliaceae -son de importancia en los ecosistemas tropicales, sobre todo en las fases de regeneración de éstos. La familia incluye aproximadamente 50 géneros y 450 especies. El género con mayor número de especies es Grewia (150), presente en África, Asia y Australia. En los trópicos de América el género más diverso es Triumfetta (43). Corchorus es el único género de la familia que comprende especies con hábito herbáceo o sufrutescente, con aproximadamente 40 especies de distribución pantropical (Cronquist, 1981; Heywood, 1985; Mabberley, 1993; Halford, 1995). En México se conocen seis especies, las cuales son propias de vegetación secundaria como arvenses y ruderales, aunque se les ha reportado también en bosque tropical caducifolio y de galería (Gual, 1998; Colmenero y Fernández-Nava, 2003).

El origen del vocablo genérico Corchorus proviene del griego korkhoros, un antiguo nombre dado a algunas plantas herbáceas alucinógenas (Brizicky, 1965; Halford, 1995). Este género incluye especies de importancia económica, como $C$. capsularis L. y $C$. olitorus L., las cuales son la principal fuente de fibra ("el yute"), de uso comercial en Asia y África. En Estados Unidos (Islas Vírgenes) y Centroamérica (Guatemala y Panamá) las hojas y tallos jóvenes de $C$. aestuans L. son consumidos como alimento y usados en la medicina tradicional (Standley y Steyermark, 1946; Robyns, 1964; Brizicky, 1965); en Ghana e India se ha utilizado para combatir enfermedades como gonorrea, neumonía, infecciones estomacales y de vías urinarias (Anónimo, 2008); C. siliquosus L. en Haití, se ha utilizado como antiinflamatorio, emoliente, expectorante y sedante (Anónimo, 2008). En México, $C$. siliquosus es utilizado en padecimientos del hígado, riñón, oído, enfermedades venéreas y como antiinflamatorio, además de ser usado para la

\title{
Nuevo ReGistro de Corchorus CAPSULARIS (TILIACEAE) PARA LA FLORA DE MÉXICO
}

\author{
Martha Gual-Díaz ${ }^{1}{ }^{2}$, Nelly Diego-Pérez ${ }^{1}$ y \\ Oswaldo Téllez-VAldÉS ${ }^{3}$ \\ 'Laboratorio de Plantas Vasculares, Departamento de Biología, \\ Facultad de Ciencias, UNAM, Coyoacán 04510, México, D.F. \\ ${ }^{3}$ Laboratorio de Recursos Naturales, FES Iztacala, UNAM, UNIPRO. \\ ${ }^{2}$ Autor para correspondencia. Correo-e: mgual@xolo.conabio.gob.mx
}

elaboración de té (Aguilar et al., 1994; Anónimo, 2008). En particular, Corchorus capsularis es una especie con gran importancia económica en India. Esta especie junto con $C$. olitorus, son ampliamente cultivadas para la obtención de "jute", que es considerado a nivel mundial como la segunda fibra natural más importante después del algodón. La distribución natural de estas especies es a lo largo de las regiones tropicales de Australia, China e India. De acuerdo con Edmonds (1990), C. capsularis es originalmente nativa del sureste de China y ampliamente distribuida en Asia a través de su cultivo, donde se le encuentra escapada en estado silvestre.

En la revisión de ejemplares de los herbarios FCME, MEXU y ENCB, para la elaboración del tratamiento de la familia Tiliaceae, la cual forma parte del proyecto "Flora de Guerrero", se detectó una colecta del género Corchorus, la cual no coincidía morfológicamente con las seis reportadas para México. Esta especie se distingue de las otras especies por importantes diferencias como flores con disco estaminal evidente, ovario 5-locular, fruto capsular globoso y rugoso, ligeramente 5-costado. La revisión de especimenes del herbario de Berlín (B) y bibliográfica especializada permitió asignar el nombre de Corchorus capsularis al espécimen, especie que se registra por primera vez para la flora de México.

Corchorus capsularis L., Sp. Pl. 529. 1753. Tipo: Ceylan. (Holotipo: BM; microficha IDC 177-12, 356, 1, 3, LINN-691.3 MEXU!). Figura 1.

Arbustos hasta de $1.5 \mathrm{~m}$ de alto. Tallos glabros. Hojas con láminas lanceoladas, de 4 a $10 \mathrm{~cm}$ de largo, 1.4 a $3.3 \mathrm{~cm}$ de ancho, haz con pubescencia estrigosa en los nervios, envés glabro, ápice largo acuminado, base cuneada o redondeada, con los dientes basales prolongados formando dos caudas; pecíolos de 0.9 a $1.6 \mathrm{~cm}$ de largo, sólo con el haz estrigoso; estípulas ca. $6 \mathrm{~mm}$ de largo, rojizas. Flores ca. 5 mm de diámetro; sépalos cuculados, ca. $3 \mathrm{~mm}$ de largo, ca. $1 \mathrm{~mm}$ de ancho, envés estriguloso; pétalos obovados o espatulados, ápice redondeado, ca. $3 \mathrm{~mm}$ de largo, ca. $1.2 \mathrm{~mm}$ de ancho; disco estaminal festonado, blanco; estambres 25, filamentos ca. $1.5 \mathrm{~mm}$ de largo; gineceo 5-carpelar; ovario globoso, obcónico, 5-locular, 2 hileras de 
GuAL-Díaz ET AL.

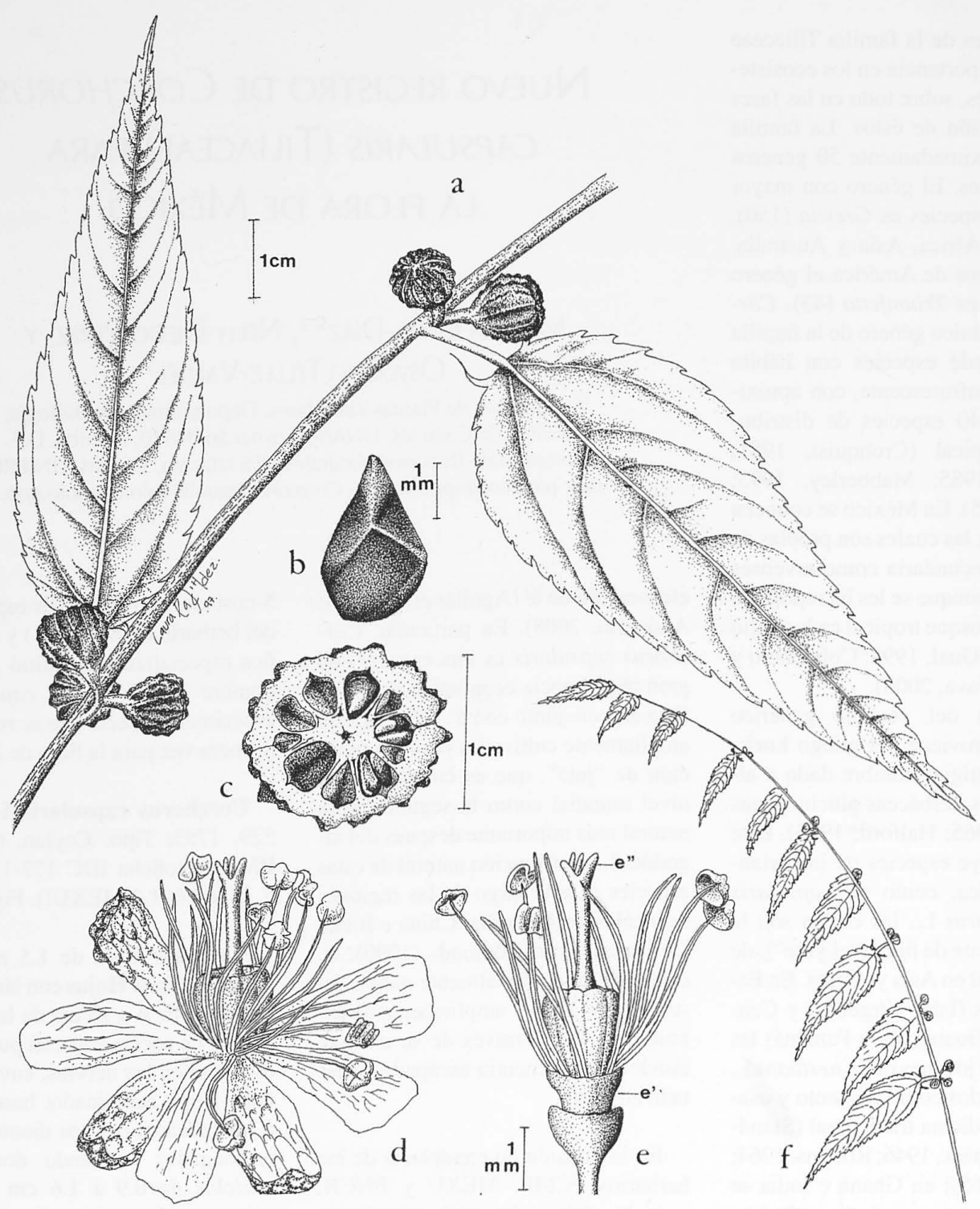

Figura 1. Corchorus capsularis. a. Rama con hojas y frutos. b. Semilla vista dorsal. c. Corte transversal del fruto. d. Flor. e. Vista longitudinal de la flor sin los pétalos. f. Rama con flores (con base en N. Diego \& R. Oviedo 6659).

óvulos por lóculo. Cápsula globosa, obcónica, 5-costada, 1.2 a $1.5 \mathrm{~cm}$ de largo, 1.0 a $1.3 \mathrm{~cm}$ de ancho, oscura, rugosa, ápice obtuso. Semillas lisas, piriformes, ca. $3 \mathrm{~mm}$ de largo, ca. 2 mm de ancho, castaño oscuras.

La siguiente clave para la identificación de las especies de Corchorus presentes en México, muestra que la característica más conspicua e im- portante para el reconocimiento de C. capsularis es la forma globosa del fruto, que contrasta con el patrón linear presente en las otras seis especies. 
Clave para la identificación de las siete especies de Corchorus presentes en México

1. Flores con disco estaminal evidente. 2. Estambres 50; ovario 5-locular; cápsula globosa. .C. capsularis

2. Estambres 30-50; ovario 5-6locular; cápsula cilíndrica. C. olitorius

1. Flores con disco estaminal no evidente.

3. Ovario estrigoso o adpreso; ápice de la cápsula obtuso o con 3 o 4 dientes bífidos.

4. Sépalos sin apéndices en el ápice; cápsula comprimida C. siliquosus

4. Sépalos con apéndices en el ápice; cápsula 3 o 4 angulada........ C. aestuans

3. Ovario piloso o híspido; ápice de la cápsula acuminado y sin dientes.

5. Pétalos obtrulados; cápsula bilocular, densamente estrigosa........ C. hirtus

5. Pétalos obovados o espatulados; cápsula trilocular, glabra o con pubescencia adpresa.

6. Estambres de 20-40; cápsulas 2 valvadas C. orinocensis

6. Estambres de 5-40; cápsulas 3 valvadas

C. trilocularis

La presencia de $C$. capsularis en la costa occidental de México puede deberse a la influencia humana. Los viajes navieros de China ("Nao de China") y Filipinas ("Galeón de Manila") hacia Acapulco, así como las ferias comerciales que se desarrollaban en este mismo puerto en el siglo XVIII han sido documentados desde la antigüedad (González, 1989), pudiendo ser estas las vías para su llegada a América. Sin embargo, su distribución esporádica y tan restringida sugieren una introducción mucho más reciente al continente, probablemente por el intercambio de granos, vegetales y ganado por vía marítima desde Asia.

El especimen de Corchorus capsularis colectado por N. Diego \& R. Oviedo 6659 en Guerrero está depositado en el herbario FCME. No obstante, los esfuerzos efectuados por el Laboratorio de Plantas Vasculares de la Facultad de Ciencias UNAM, para localizar otros individuos de esta especie, no dieron resultados positivos, ya que durante varios años consecutivos se intentó recolectar nuevamente esta especie en la laguneta "El Carrizal" y sitios aledaños sin éxito alguno, probablemente la especie ya no existe en el sitio de recolecta por lo que se requiere realizar colectas intensivas para tratar de localizarla en otros estados.

\section{Agradecimientos}

Agradecemos al Dr. Rafael Fernández Nava y al M. en C. Aurelio Colmenero por la espera paciente del escrito, así como al M. en C. Rafael Torres Colín y a los Drs. José Luis Villaseñor Ríos y Sergio Zamudio por la revisión, observaciones y comentarios críticos. El toque especial de éste, es la ilustración que lo acompaña, elaborada por la Biól. Laura Padilla.

\section{Literatura citada}

Aguilar A., Camacho J.R., Chino S., Jácquez P. \& López M. E. 1994. Herbario
Medicinal del Instituto Mexicano del Seguro Social. Información etnobotánica. Instituto Mexicano del Seguro Social. México, D.F.

Anónimo. 2008. http://ukcrop.net/perl/ace/ tree/EthnobotDB?name=Corchorus\&c ass $=$ Genus

Brizicky G.K. 1965. The genera of Tiliaceae and Elaeocarpaceae in the southeastern United States. Journal of the Arnold Arboretum 46: 286-307.

Colmenero R.J.A y Fernández-Nava R. 2003. New record of Corchorus (Tiliaceae) for Mexico. Sida, Contributions to botany 20: 1299-1309.

Cronquist A. 1981. An integrated system of classification of flowering plants. Columbia University Press, New York.

Edmonds J.M. 1990. Herbarium Survey of African Corchorus L. Species. Systematic and Ecogeographic Studies on Crop Genepools No. 4. International Board of Plant Genetic Resources, Rome, Italy. 284 pp.

González C.V. 1989. Malaspina en Acapulco. Gobierno Constitucional del Estado de Guerrero, Turner Libros S. A. Madrid.

Gual D.M. 1998. La familia Tiliaceae Juss., en el Estado de Guerrero, México. Tesis de Maestría (Biología Vegetal) Facultad de Ciencias, Universidad Nacional Autónoma de México, México, D.F.

Halford D.A. 1995. Notes on Tiliaceae in Australia, 2. A revision of the simplehaired species of the genus Corchorus 1. Austrobaileya 4: 297-320.

Heywood V.H. 1985. Las plantas con flores. Reverté, Barcelona, España.

Mabberley D.L. 1993. The plant-book. A portable dictionary of the higher plants. Cambridge University Press, UK.

Robyns A. 1964. Flora of Panamá, part IV. Tiliaceae. Annals of the Missouri Botanical Garden 51: 1-35.

Standley P.C. y J.A. Steyermark 1946. Tiliaceae. Flora de Guatemala. Fieldiana Botany 24: 30-48. 